\title{
Publisher's Note to: Editors must be vigilant to guarantee the quality and credibility of published scientific work
}

\author{
Springer-Verlag GmbH Austria, part of Springer Nature ${ }^{1}$
}

Published online: 19 August 2019

(c) Springer-Verlag GmbH Austria, part of Springer Nature 2019

We were informed by Kyle R. Fluegge and Keith R. Fluegge (hereafter "the Authors") of their opinion that the Editorial Editors must be vigilant to guarantee the quality and credibility of published scientific work (Gerlach 2018) is one-sided in its claim that the article Glyphosate use predicts ADHD hospital discharges in the healthcare cost and utilization project net (HCUOnet): a two-way fixed-effects analysis (Fluegge and Fluegge 2015)—which they authored and was later retracted by the Publisher-is an example of studies that compromise the quality and credibility of the scientific record. The Authors requested that their views in this regard be published.

The Authors claim that, although the retraction note was correctly cited in the Editorial, there are additional sources to be taken into consideration in order to understand the nature of the retraction. A note published on Retraction Watch (2015) indicated that the retracted article had been peer-reviewed and duly accepted before its publication, in contrast to what the retraction note implied. Furthermore, the Authors point out that a peer-reviewed version of the article was published in another journal shortly after the retraction (Fluegge and Fluegge 2016).

In addition, the Authors object to being designated "nonscientists". Kyle Fluegge claims that he completed his academic studies with several degrees ( $\mathrm{PhD}, \mathrm{MPH}, \mathrm{MA})$ and is currently employed as an economist at the New York City Department of Health and Mental Hygiene. Keith Fluegge, the first author of the retracted paper, claims that he has academic training in psychology with a special interest in neurodevelopment.

This Publisher's Note refers to the article available at https://doi. org/10.1007/s12402-018-0275-8.

Springer-Verlag GmbH Austria, part of Springer Nature

http://www.springer.com

1 Wien, Austria
The Authors deny the allegation that they made false statements regarding potential conflicts of interest. They claim that the Institute of Health and Environmental Research is not a private institute but a public charity in the US, with certified non-profit status. Accordingly, the Authors maintain that the statement from the retracted paper regarding conflicts of interest is accurate.

Springer Nature remains neutral with regard to these claims, and to the content of the Editorial.

\section{References}

Fluegge KR, Fluegge KR (2015) Glyphosate use predicts ADHD hospital discharges in the healthcare cost and utilization project net (HCUOnet): a two-way fixed-effects analysis. PLoS ONE 10(8):e0133525. https://doi.org/10.1371/journal.pone.0133525

Fluegge KR, Fluegge KR (2016) Glyphosate use predicts healthcare utilization for ADHD in the Healthcare Cost and Utilization Project net (HCUPnet): a two-way fixed effects analysis. Pol J Environ Stud 25(4):1489-1503

Gerlach M (2018) Editors must be vigilant to guarantee the quality and credibility of published scientific work. ADHD Atten Def Hyp Disord 10:245. https://doi.org/10.1007/s12402018-0275-8

Retraction Watch (2015) A mess: PLOS mistakenly publishes rejected ADHD-herbicide paper, retracts it. https://retractionwatch .com/2015/08/26/a-mess-plos-mistakenly-publishes-rejectedadhd-herbicide-paper-retracts-it/

Publisher's Note Springer Nature remains neutral with regard to jurisdictional claims in published maps and institutional affiliations. 